\title{
Factors associated with abnormal glomerular filtration rate among HIV-positive children at the University of Maiduguri Teaching Hospital, Maiduguri, Nigeria
}

\author{
Halima Umar Ibrahim', Adamu Ibrahim Rabasa², Hassan Abdullahi Elechi², Abubakar Garba Farouk, Isa Hassan Saidu', \\ Lawan Bukar Maryah² \\ 'Department of Paediatrics, Federal Medical Centre, Birnin-Kudu, Nigeria; '2Department of Paediatrics, University of Maiduguri, \\ Maiduguri, Nigeria.
}

\section{ABSTRACT}

Background: Renal disease is commonly encountered in patients with HIV infection. The estimated glomerular filtration rate (eGFR) provides a good assessment of the renal function and is widely used in screening populations that are at risk of renal dysfunction. We determined the prevalence of abnormal eGFR among HIV-positive children and factors associated with it.

Methods: In a cross-sectional study, children aged 15 years and below were recruited through systematic random sampling from the Paediatrics Infectious Disease Clinic of the University of Maiduguri Teaching Hospital until the desired sample size of 250 was reached. Clinical and laboratory information was obtained from the patient records and used for clinical staging and immunological classification. Serum creatinine was measured using Jaffe's reaction and eGFR calculated using the Schwartz formula. The data obtained were analysed using SPSS version 16.

Results: A total of 157 (62.8\%) children were on antiretroviral therapy (HAART) for periods ranging from I to I68 months (mean duration $66.1 \pm 46.5$ months). Ninety-three (37.2\%) children had advanced disease representing WHO clinical stages 3 and 4, whereas 103 (41.2\%) had advanced or severe immunosuppression. The mean eGFR of the study population was $102 \pm 41 \mathrm{~mL} / \mathrm{min} / 1.73 \mathrm{~m}^{2}$. Fifty-two children (20.1\%) had low eGFR ( $<2$ SD below the mean eGFR for age and sex) and 6 (2.4\%) had high eGFR ( $>2$ SD above the mean eGFR for age and sex). A total of 23 (9.2\%) children had moderate to severe renal impairment, defined as eGFR $<60 \mathrm{~mL} / \mathrm{min} / 1.73 \mathrm{~m}^{2}$. Age, sex, socio-economic status, mode of transmission as well as history of HAART usage were not significantly associated with abnormal eGFR. However, relatively shorter duration of treatment with HAART, as well as advanced clinical or immunological stage were all significantly associated with abnormal eGFR.

Conclusion: Renal dysfunction is common among children with HIV disease in Maiduguri with over a third of those affected having moderate to severe renal dysfunction. Abnormal renal function is more frequent among children with advanced clinical and immunological disease. We recommend the regular determination of eGFR and early initiation of HAART in all children with HIV disease.

Keywords: HIV infection, estimated glomerular filtration rate, renal dysfunction, children.

\section{INTRODUCTION}

The global HIV and AIDS scourge constitutes an important public health issue, particularly in sub-Saharan Africa [I]. Nigeria harbours the largest number of HIVpositive children in the world [2]. With continuously improving access to diagnosis, these children are increasingly surviving into adolescence and adulthood. Thus, HIV infection in children now runs a chronic course with long-term multisystem complications such as renal and cardiac disease [3-5]. 
The kidney is a primary target organ in HIV infection. Although the mechanism remains poorly understood direct viral invasion and genetic factors are known to play significant roles [6-9]. A variety of renal disorders may occur through the course of HIV infection. These can be acute or chronic [10] and manifest through a spectrum of clinical syndromes including HIV-associated nephropathy (HIVAN), acute tubular dysfunction, fluid and electrolyte abnormalities or renal failure caused by infectious diseases and nephrotoxic drugs. Immune-mediated glomerulopathies (IgA, lupus-like syndromes) and HIV-associated thrombotic microangiopathies are not uncommon [10]. These disorders may lead to chronic kidney disease. In addition, several drugs used in the management of HIV infection and AIDS require dose adjustment or are contraindicated in the presence of declining renal function [II]. Consequently, routine screening and periodic evaluation for renal abnormalities have been generally accepted in the management of children living with HIV [II].

Glomerular filtration rate (GFR) remains the best test in assessing the level of kidney function and determining the stage of kidney disease. Estimated glomerular filtration rate (eGFR), calculated from the serum creatinine concentration, is widely used in lieu of measured GFR, due to the ease of its determination. The eGFR formulae are based on predicted 24-hour creatinine excretion rate, which is a function of the muscle mass. Hence, eGFR may be erroneously low or high in highly muscular and very lean individuals, respectively [12]. eGFR has been shown to have a higher sensitivity in detecting renal dysfunction among HIV-positive children when compared with other commonly used parameters like proteinuria $[|3| 4$,$] .$

Several studies have reported varying prevalence of abnormal eGFR among HIV-positive children. Fredrick et al. [15] studied 240 children in Tanzania and found $65.4 \%$ of them with eGFR $<90 \mathrm{~mL} / \mathrm{min} / 1.73 \mathrm{~m}^{2}, 14$ (5.8\%) of whom had eGFR of 30-59 mL/min/1.73 $\mathrm{m}^{2}$. Low CD4 percent and lower CD4 counts were associated with higher prevalence of microalbuminuria and significant proteinuria. Dondo et al. [16] from Zimbabwe reported low eGFR $\left(<90 \mathrm{~mL} / \mathrm{min} / 1.73 \mathrm{~m}^{2}\right)$ in $34.6 \%$ with 2 children (1\%) having eGFR of $<60 \mathrm{~mL} / \mathrm{min} / 1.73 \mathrm{~m}^{2}$. Older children and those with $\mathrm{WHO}$ clinical stage 4 disease were more likely to have low eGFR. In another study, from Abuja, Nigeria, Okechukwu et al. [17] reported a prevalence of low eGFR among 26.7\%, 2 (1.2\%) of whom had eGFR of $<60 \mathrm{~mL} /$ $\mathrm{min} / 1.73 \mathrm{~m}^{2}$. In a related study, Iduoriyekemwen et al. [ 18 ] reported low eGFR in $5.1 \%$ of the children they studied in Benin, Nigeria. None of these children with low eGFR had significant proteinuria or microalbuminuria. They also found advanced clinical stages (WHO clinical stages 3 and 4) to be associated with renal disease.

Although several African studies have reported on the prevalence of abnormal eGFR among HIV-infected children, most have focused on factors associated with proteinuria or macroalbuminuria. Abnormal eGFR may exist in the absence of other markers of renal disease [18]. We therefore conducted this study among HIV-positive children in our centre to determine the prevalence of abnormal eGFR and to identify any associated risk factors.

\section{METHODS}

This cross-sectional, descriptive study was conducted between February and October 2014 at the Paediatric Infectious Disease Clinic of the University of Maiduguri Teaching Hospital, Borno State, located in the NorthEastern region of Nigeria. The Infectious Disease Clinic has an average patient load of 50-60 patients per week.

We recruited HIV-infected children (two positive DNA polymerase chain reaction tests for those aged $<18$ months and two positive antibody tests for older children) aged 15 years and below. The minimum sample size was calculated at 250 participants using Taylor's formula [19], with the prevalence of abnormal GFR estimated at $20.5 \%$ based on a previous study [20].

Participants were recruited by using simple balloting to select one child from the first four to register at the clinic for the day, and thereafter every fourth child. In the case of non-eligibility or unwillingness to participate, the very next eligible patient was selected. Children with sickle cell anaemia, hepatitis B infection or hepatitis C infection were excluded. Enrolment continued until the target of 250 participants was reached.

The study was approved by the Research and Ethics Committee of UMTH. Informed consent was obtained from the parents or caregivers. The eGFR results were discussed with parents and caregivers and those children with abnormal results were referred to the nephrology unit for further evaluation.

\section{Study procedures}

Demographic and clinical information, including anthropometric measurements, were recorded using a structured data capture sheet. Weight and height were measured to the nearest $0.05 \mathrm{~kg}$ and $0.5 \mathrm{~cm}$, respectively, using a Wunder stadiometer fitted with a calibrated weighing scale. The height was measured with the child standing erect and the head positioned such that the Frankfurt plane was 
horizontal, feet together, knees straight and heels, buttocks, shoulder blade and occiput in contact with the vertical surface of the stadiometer. The height measurement was taken with the examiner's eyes at the level of the headboard. For younger children or ill patients who could not stand erect, a measuring board was used with the help of an assistant. Socio-economic status of the children was determined from the parents' educational level and occupation using Oyedeji's model [2I]. The clinical features and anthropometry were used to stage the patients as per the $\mathrm{WHO}$ clinical staging for infants and children [22]. WHO clinical stages $I$ and 2 were considered as non-advanced disease and stages 3 and 4 as advanced disease. Age categorization was based on the $\mathrm{WHO}$ immunological classification of HIV infection in children [22].

Venous blood samples in an ethylene diamine tetra-acetic acid (EDTA) bottle was used for measurement of the CD4+ count and CD4+\%; blood in a lithium heparin bottle was used for creatinine estimation. All samples were analysed on the day of collection.

Screening for hepatitis B surface antigen ( $\mathrm{HBsAg}$ ) and hepatitis $\mathrm{C}$ virus antibody ( $\mathrm{HCV} \mathrm{Ab}$ ) was carried out using the HBsAg and HCV Ab Gold rapid screening test (Micropoint Biotechnologies, China). Patients found to be positive for either $\mathrm{HBsAg}$ or $\mathrm{HCV}$ Ab were excluded from the study.

The CD4+ count and CD4+\% (for children $<5$ years) was obtained by using a Partec ${ }^{\text {TM }}$ flow cytometer and CD4+ easy count kit (Görlitz, Germany). Using the WHO agerelated CD4 count and CD4\% values, the children were stratified into four groups: no significant immunosuppression, mild immunosuppression, advanced immunosuppression, and severe immunosuppression [22]. For the purpose of this study, the no significant and mild immunosuppression groups were combined as non-severe immunosuppression, whereas the advanced and severe suppression groups were combined as severe immunosuppression.

Serum creatinine level was estimated using a standard method based on Jaffe's reaction [23] on a Jenway ${ }^{\top M}$ colorimeter at the UMTH Chemical Pathology Laboratory by an experienced laboratory scientist. GFR was estimated using the Schwartz formula [12]. The ranges for normal eGFR (in $\mathrm{mL} / \mathrm{min} / 1.73 \mathrm{~m}^{2}$ ) were $96 \pm 22$ (for children $<2$ years), 133 \pm 27 (for those aged 2-12 years), $140 \pm 30$ (for males aged |3-2| years) and $126 \pm 26$ (for females aged |3-2| years) [24]. Values less than 2 SD below the mean for the age and sex were considered as corresponding to
The data were analysed using SPSS version 16.0. Continuous variables were expressed as means + standard deviation $(\mathrm{M} \pm \mathrm{SD})$, while categorical variables were summarised using frequencies. Student's t-test was used to test differences between means, and chi-squared and Fisher's exact tests were used for categorical variables. A p value of $<0.05$ was considered significant.

\section{RESULTS}

A total of 250 patients were recruited. Their socio-demographic characteristics are summarised in Table I. The children were aged between 5 and 180 months (mean 89 \pm 48 months) and $46.4 \%$ were male. Most were aged $\geq 60$ months and $55 \%$ were of lower social class.

The treatment modalities, mode of HIV transmission and disease severity are shown in Table 2. A total of 157

Table I. Socio-demographic characteristics of the study population.

\begin{tabular}{|lcc|}
\hline Variables & Frequency & Percentage (\%) \\
\hline Age (months) & 18 & 7.2 \\
$0--12$ & 69 & 27.6 \\
$13-59$ & 163 & 65.2 \\
$>60$ & & \\
Sex & 116 & 46.4 \\
Male & 134 & 53.6 \\
Female & & \\
Social class & 40 & 16.0 \\
Upper & 73 & 29.2 \\
Middle & 137 & 54.8 \\
Lower & & \\
\hline
\end{tabular}

Table 2. Medication use, modes of transmission, disease severity, and immunosuppression among the study population.

\begin{tabular}{lcc|} 
Variables & Frequency & Percentage (\%) \\
\hline Medication & & \\
On HAART & 157 & 62.8 \\
HAART naïve & 93 & 37.2 \\
Mode of transmission & & \\
Vertical & 231 & 92.4 \\
Blood transfusion & 5 & 2.0 \\
Unknown & 14 & 5.6 \\
Disease severity & & \\
Non-advanced HIV disease & 157 & 62.8 \\
Advanced HIV disease & 93 & 37.2 \\
Immunosuppression & & \\
Non-severe & 147 & 58.8 \\
Severe & 103 & 41.2 \\
\hline
\end{tabular}




\begin{tabular}{|c|c|c|c|c|}
\hline \multicolumn{5}{|c|}{$\begin{array}{l}\text { Glomerular } \\
\text { filtration rate }\end{array}$} \\
\hline & $\begin{array}{c}\text { Abnormal } \\
\mathrm{n}(\%)\end{array}$ & $\begin{array}{c}\text { Normal } \mathrm{n} \\
(\%)\end{array}$ & $\chi^{2}$ & $P$ value \\
\hline \multicolumn{5}{|l|}{ Age (months) } \\
\hline $0--12$ & $2(11.1)$ & $16(88.9)$ & 1.64 & 0.440 \\
\hline $13-59$ & $16(23.2)$ & $53(76.8)$ & & \\
\hline$>60$ & $40(24.5)$ & $123(75.5)$ & & \\
\hline \multicolumn{5}{|l|}{ Sex } \\
\hline Male & $30(25.9)$ & $86(74.1)$ & 0.86 & 0.350 \\
\hline Female & $28(20.9)$ & $106(79.1)$ & & \\
\hline \multicolumn{5}{|l|}{ Social class } \\
\hline Upper & $14(35.0)$ & $26(65.0)$ & 8.39 & 0.015 \\
\hline Middle & $9(12.3)$ & $64(87.7)$ & & \\
\hline Lower & $35(25.5)$ & $102(74.5)$ & & \\
\hline \multicolumn{5}{|c|}{ Mode of transmission } \\
\hline Vertical & $53(22.9)$ & $178(77.1)$ & 0.26 & 0.876 \\
\hline Blood transfusion & I (20.0) & $4(80.0)$ & & \\
\hline Unknown & $4(28.6)$ & $10(7 \mid .4)$ & & \\
\hline \multicolumn{5}{|l|}{ Medication } \\
\hline On HAART & $33(21.0)$ & $124(79.0)$ & 1.13 & 0.288 \\
\hline HAART naïve & $25(26.9)$ & $68(73.1)$ & & \\
\hline \multicolumn{5}{|c|}{ Duration on HAART } \\
\hline$<1$ year & $13(43.3)$ & $17(66.7)$ & 13.07 & 0.001 \\
\hline $1-5$ years & II (22.0) & $39(78.0)$ & & \\
\hline$>5$ years & $9(11.7)$ & $68(88.3)$ & & \\
\hline \multicolumn{5}{|l|}{ Disease severity } \\
\hline Non-advanced & $19(12.1)$ & I 38 (87.9) & 29.18 & $<0.00$ I \\
\hline Advanced & $39(41.9)$ & $54(58.1)$ & & \\
\hline \multicolumn{5}{|c|}{ Immunosuppression } \\
\hline NSIS & $24(16.3)$ & $123(83.7)$ & 9.46 & 0.002 \\
\hline SIS & $34(33.0)$ & $69(67.0)$ & & \\
\hline
\end{tabular}

NSIS, non-severe immunosuppression; SIS, severe immunosuppression; $\chi^{2}$, chi squared.

(62.8\%) children were on HAART for a period ranging from I to 168 months (mean duration $66 \pm 46$ months. Of those on HAART, 143 (91.1\%) were on a regimen consisting of zidovudine, lamivudine and nevirapine. The remaining 14 patients were on regimens including either abacavir or efavirenz in place of nevirapine. Twenty (8\%) of the 250 subjects were on anti-TB treatment, and 6 of these were on HAART. The majority of the participants had acquired the infection through vertical transmission. The mode of transmission was uncertain in 14 patients, who were mostly adolescents. A total of 93 subjects (37.2\%) had advanced disease; 103 (41.2\%) were severely immunosuppressed.
The mean eGFR of the study population was $102 \pm 41 \mathrm{~mL} /$ $\mathrm{min} / 1.73 \mathrm{~m}^{2}$. A total of $192(76.8 \%)$ had normal eGFR whereas 58 (23.2\%) had abnormal eGFR. Of the 58 with abnormal eGFR, 52 (20.8\% of the total) and 6 patients had low and high values, respectively. Twenty-three subjects (9.2\%) had moderate to severe renal impairment as defined by eGFR $<60 \mathrm{~mL} / \mathrm{min} / 1.73 \mathrm{~m}^{2}$.

Although higher frequencies of abnormal eGFR were observed in children >60 months, among males and in children of low socio-economic status, the differences were not statistically significant. Modes of transmission and history of HAART medication were also not associated with abnormal eGFR. However, HAART treatment of short duration, as well as advanced clinical or immunological stage were all associated with abnormal eGFR $(p<0.05)$.

\section{DISCUSSION}

The low eGFR rate of I in 5 children which we report emphasises the high burden of renal disease among this group of children. An even higher prevalence of low eGFR (43.4\%) was reported by Ezeonwu et al. [25] from Enugu, Nigeria, among children of similar age. Moderate to severe renal impairment (eGFR $<60 \mathrm{~mL} / \mathrm{min} / 1.73 \mathrm{~m}^{2}$ ) was very common in this study, accounting for $44.2 \%$ of those with low eGFR. This is comparable with that reported by Esezobor et al. [26] from Lagos and Wools-Kaloustian et al. [27] from Kenya.

The slightly higher prevalence reported by Dondo et al. [ I6] from Zimbabwe may be due to the difference in methods of estimating the GFR. The modified Counahan-Barratt formula was used in the Zimbabwean study whereas we used the Schwartz formula, which tends to overestimate the GFR [29].

In contrast, Iduoriyekemwen et al. [18] reported a substantially lower prevalence of $5.1 \%$ from Benin, whereas Ezeonwu et al. [25] did not find any child with eGFR $<60$ $\mathrm{mL} / \mathrm{min} / 1.73 \mathrm{~m}^{2}$ in their study from Enugu. In both of these studies, most of the patients were on HAART (100\% in the Iduorivekemwen study and $77.4 \%$ in that by Ezeonwu et al.). In our study, 37.2\% of the participants were not on HAART. In addition, our participants were older, implying longer exposure to the damaging effect of the virus. Furthermore, while $37.2 \%$ of the children in our study had advanced disease, only $4.4 \%$ of the children studied by Ezeonwu et al. [25] had the same disease severity.

The younger children in our study had a lower frequency of abnormal eGFR, although this trend was not statistically significant. Other studies have demonstrated associations 
between age and abnormal eGFR [16,25]. In our study there were very few children aged one year and below.

HAART naivety was associated with a higher prevalence of abnormal eGFR. This relationship was further highlighted by the inverse relationship between duration of HAART usage and prevalence of abnormal eGFR. The use of HAART may reduce the direct effect of HIV on the renal cells and maintain or improve renal function [30]. Similar to previous studies [16,26], advanced HIV disease and severe immunosuppression were associated with higher prevalence of abnormal eGFR. Abnormally high eGFR values were recorded in a few patients in our study. This may indicate hyperfiltration or may reflect poor nutritional status as low lean muscle mass affects serum creatinine concentrations and thus leads to over-estimation of GFR using the Schwartz formula [26].

Our study had some limitations. We were not able to measure urine protein excretion and it is possible that some children with normal eGFR could have had proteinuria, an important marker of HIVAN and other types of renal disease. Also, we relied on eGFR as a marker of renal function and this has its limitations as mentioned above.

\section{CONCLUSIONS}

Abnormal renal function, as detected by eGFR, is common among children with HIV disease in Maiduguri, with over a third of those affected having moderate to severe renal impairment. Abnormal eGFR is more frequent among children with advanced clinical or immunological disease, while prolonged treatment with HAART is associated with lower prevalence. We recommend routine, periodic calculation of eGFR and early initiation of HAART in all children with HIV disease.

\section{Acknowledgments}

We thank Abdulmumin Garba and Ali Ahmad for the laboratory analysis of samples.

\section{REFERENCES}

I. Panteleo G, Graziosi C, Fausi AS. The Immunopathogenesis of human immunodeficiency virus Infection: A review article. N Engl J Med. 1993; 328:327-335.

2. UNAIDS Report on the Global AIDS Epidemic. December 2010. URL http://www.unaids.org/en/resources/unaidspublications/2010/ Date accessed 20/1 1/2012.

3. Seney FD Jr, Burns DK, Silva FG. Acquired immunodeficiency syndrome and the kidney. Am J Kidney Dis. 1990; 16:1-13.

4. Ray PE, Rakusan TM, Loechelt BJ, Selby DM, Liu XH, Chandra RS. Human immunodeficiency virus associated nephropathy in the children from the Washington D.C. area; 12 years' experience.
5. Emen CP, Arogundade F, Sanusi A, Adelusola K, Wokoma F, Akinsola A. Renal disease in HIV-seropositive patients in Nigeria: an assessment of prevalence, clinical features and risk factors. Nephrol Dial Transplant. 2008; 23:74I-746.

6. Herman ES, Klotman PE. HIV-associated nephropathy: epidemiology, pathogenesis and treatment. Semin Nephrol. 2003; 23:200-208.

7. Winston JA, Bruggeman LA, Ross MD, Jacobson J, Ross L, D'Agati VD, et al. Nephropathy and establishment of renal reservoir of HIV type I during primary infection. N Engl J Med. 200 I; 344:1979- 1984.

8. Bourgoignie JJ, Ortiz-Interian C, Green DF, Roth D. Race, a cofactor in HIV-I-associated nephropathy. Transplant Proc. 1989; 21 : 3899-3901.

9. Cantor ES, Kimmel PL, and Bosch JP. Effect of race on expression of acquired immunodeficiency syndrome-associated nephropathy. Arch Intern Med. 1991; 151:125-128.

I0. Wiener NJ, Goodman JW, Kimmel PL. The HIV associated renal diseases: current insight into pathogenesis and treatment. Kidney Int. 2003; 63:1618-1631.

I I. Gupta SK, Eustace JA, Winston JA, Boydstun II, Ahuja TS, Rodriguez RA, et al. Guidelines for the management of chronic kidney disease in HIV infected patients: recommendations of the HIV Medicine Association of the Infectious Diseases Society of America. Clin Infect Dis. 2005; 40: 1559-1585.

12. Kemperman FA, Silberbusch J, Slaats EH. Glomerular filtration rate estimation from plasma creatinine after inhibition of tubular secretion: relevance of the creatinine assay. Nephrol Dial Transplant. 1999; 14:1247-1255.

13. Ira S, Shradha G, Dhaval MS, Harshal D, Mamatha L. Renal manifestations of HIV infected highly active antiretroviral therapy naive children in India. World J Pediatr. 2012; 8:252-255.

14. Warren AA, Miriam CC, Charles M, Murli P, James O, Paige LW, et al. Incidence of persistent renal dysfunction in HIV infected children, associations with use of antiretrovirals and other nephrotoxic medications and risk factors. Pediatr Infect Dis J. 2009; 28:619-625.

15. Fedrick F, Francis JM, Ruggajo PJ, Maro EE. Renal abnormalities among HIV infected children at Muhimbili National Hospital (MNH)-Dar es Salaam, Tanzania. BMC Nephrol. 2016; 17:30.

16. Dondo V, Mujuru HA, Nathoo KJ, Chirehwa M, Mufandaedza Z. Renal abnormalities among HIV-infected antiretroviral naive children, Harare, Zimbabwe. BMC Pediatr. 2013; 13:75.

17. Okechukwu AA, Lawson JO, Itanyi DU, Dalili MS. Renal function abnormalities in HIV-infected children and adolescents on antiretroviral therapy at the University of Abuja Teaching Hospital, Gwangwalada, Nigeria: A cross-sectional study. Int J Trop Dis Health. 2017; 26(4): I- 12.

18. Iduoriyekemwen NJ, Sadoh WE, Sadoh AE. Prevalence of renal disease in Nigerian children infected with the human immunodeficiency virus and on highly active anti-retroviral therapy. Saudi J Kidney Dis Transpl. 2013; 24:172-177.

19. Araoye MO. Research methodology with statistics for health and social sciences. Ilorin: Nathadex Publishers. 2003; I I 5- I 18

20. Esezobor Cl, Iroha E, Onifade E, Akinsulie AO, Temiye EO, Ezeaka C. Prevalence of proteinuria among HIV infected children attending a tertiary hospital in Lagos, Nigeria. J Trop Pediatr. 2010; 56:187-190.

21. Oyedeji GA. Socio-economic and cultural background of hospitalized children in llesha. Nig J Paediatr. 1985; I2: I I - I 17.

22. WHO Interim WHO clinical staging of HIVIAIDS \& HIVIAIDS case definitions for surveillance in African Region. Published 16/06/2005. URL www.who.int/hiv/pub/guidelines/casedefinitions/en/inndex.html. Date accessed 12/1 1/2012.

23. Narayanan Appleton HD. Creatinine: a review. Clin Chem. 1980; 26: $1119-1126$. 
24. National Kidney Foundation Kidney Disease Outcomes Quality Initiative. K/DOQI clinical practice guidelines for chronic kidney disease: Evaluation, classification, and stratification. Am J Kidney Dis. 2002; 39(2):SI-266.

25. Ezeonwu BU, Oguonu T, Okafor HU, Ikefuna AN. The use of estimated glomerular filtration rate in the evaluation of renal function in HIV-positive children in Enugu. Ann Trop Med Public Health. 20I3; 6:206-210.

26. Esezobor Cl, Iroha E, Oladipo O, Onifade E, Soriyan OO, Akinsulie $\mathrm{AO}$, et al. Kidney function of HIV-infected children in Lagos, Nigeria: using Filler's serum cystatin C-based formula. J Int AIDS Soc. 2010; 13:17.

27. Wools-Kaloustian K, Gupta SK, Muloma E, Owino-Ong'or W, Sildle J, Aubrey RW, et al. Renal disease in an antiretroviral HIV-infected outpatient population in western Kenya. Nephrol Dial Transplant. 2007; 22:2208-2212.

28. Peters PJ, Moore DM, Mermin J, Brooks JT, Downing R, Were K, et al. Antiretroviral therapy improves renal function among HIV infected Ugandans. Kidney Int. 2008; 74:925-929.

29. Gbadegesin RA, Adeyemo AA, Asinobi AO, Osinusi K. Inaccuracy of the Schwartz formula in estimating glomerular filtration rate in Nigerian children. Ann Trop Paediatr. 1997; 17(2): 179-185.

30. Chaparro Al, Mitchell CD, Abitbol CL,Wikinson JD, Baldarrago G, Lopez C, et al. Proteinuria in children infected with the human immunodeficiency virus. J Pediatr. 2008; 152:844-849.

31. Ferradini L, Jeannin A, Pinoges L, Izopet J, Odhiambo D, Mankhambo L. Scaling up of antiretroviral therapy in a rural district of Malawi: an effectiveness assessment. Lancet. 2006; 367:1335-1342. 